\title{
ENSINO COLETIVO DE VIOLÃO: UMA PESQUISA BIBLIOGRÁFICA NOS ANAIS DOS ENCONTROS DA ABEM ENTRE OS ANOS 2003-2017
}

ENSEÑANZA COLECTIVA DE LA GUITARRA: UNA INVESTIGACIÓN BIBLIOGRÁFICA EN LAS ACTAS DE LOS ENCUENTROS ANUALES DE LA ABEM ENTRE 2003-2017

COLLECTIVE GUITAR LEARNING: A BIBLIOGRAPHIC RESEARCH FROM THE ABEM ANNUAL-MEETING PROCEEDINGS BETWEEN 2003 AND 2017

Carlos Augusto Amat y León Correa *

Correo electrónico: carlos-alc5@hotmail.com

Fecha recibido: 16 de agosto de 2020

Fecha de aprobación: 21 de enero de 2021

\footnotetext{
Carlos Amat y León es Licenciado en educación musical por la Universidad Federal de São Carlos (UFSCar) en Brasil; con formación en los campos de la docencia/ pedagogía musical e integración cultural en la Universidad Nacional de Rosario (UNR) en Argentina. Además diplomado en performance instrumental por el Conservatorio de Tatui en Brasil. Actualmente cursa el master en "Estudios Latinoamericanos: Cultura y Gestión” de la Universidad de Granada en España.
} 


\section{Resumo}

Esta pesquisa teve como objetivo geral mapear e analisar as publicações acerca do ensino coletivo de violão nos Anais dos Encontros s da ABEM entre os anos 2003- 2017. A partir do método de pesquisa bibliográfica, a investigação categorizou e analisou as publicações nesta fonte de divulgação cientifica específica. Através da análise e reflexões sobre os materiais coletados, foram identificadas 51 publicações já realizadas na temática no período 2003-2017; realizou-se a quantificação de incidências das palavras chave; identificou-se 22 trabalhos de pesquisa e outros 29 de relatos de experiência, os quais foram categorizados pelos seus objetivos correspondentes; da mesma forma categorizou-se os níveis acadêmicos dos trabalhos, separados por aqueles que são de monografia, mestrado, doutorado e especialização. Finalmente, identificou-se os contextos sociais e culturais que permeiam o desenvolvimento das práticas ou investigações encontradas.

Palavras chave: ensino coletivo de violão, pesquisa bibliográfica, anais dos Encontros da ABEM.

\section{Abstract}

The overall objective of this investigation was to map and analyze the scientific publications concerning collective guitar learning, issued in the proceedings of the annual meeting of the ABEM between 2003 and 2017. Through bibliographic research, the publications from this source have been categorized and analyzed. In the analysis of the collected data, 51 works related to the topic and published between 2003 and 2017 were identified, the frequency of keywords was counted, and 22 research papers and 29 articles sharing experiences were found and were categorized thematically. The works were also categorized according to academic levels; they were separated into categories corresponding to undergraduate, post-graduate, and doctoral theses or dissertations, and works done within specialized programs outside of a degree track. Finally, the social and cultural context that influenced the development of the research process was also identified.

Keywords: Collective guitar learning, bibliographic research, annual proceedings of ABEM.

\section{Resumen}

Esta investigación tuvo como objetivo general mapear y analizar las publicaciones sobre de la enseñanza colectiva de la guitarra en las actas de los encuentros anuales dela ABEM entrelos años 2003-2017. Por medio del método de investigación bibliográfica, el presente trabajo categorizó y analizó las publicaciones en esta fuente de divulgación científica específica. A través del análisis y reflexiones sobre los datos recolectados fueron identificadas 51 publicaciones ya realizadas en esta temática entre el periodo 2003-2017; se hizo la cuantificación de frecuencias de aparición de las palabras claves; se identificaron 22 trabajos de investigación y otros 29 de relatos de experiencia, los cuales se categorizaron a partir de sus objetivos correspondientes; del mismo modo se categorizaron los grados académicos de cada trabajo, separados por aquellos que se trataban de monografías de grado, maestría, doctorado y especialización. Finalmente se identificaron los contextos sociales y culturales que inciden en el desarrollo de las prácticas o investigaciones encontradas.

Palabra clave: Enseñanza colectiva de la guitarra, investigación bibliográfica, actas de los encuentros anuales de la ABEM. 


\section{Introdução}

Este artigo é uma síntese do meu trabalho de conclusão de graduação o qual teve como objetivo geral mapear as publicações de divulgação cientifica existentes sobre o ensino musical coletivo de violão nos Anais dos Encontros da Associação Brasileira de Educação Musical (ABEM) entre os anos 2003-2017.

A escolha dessa fonte de pesquisa se deve ao fato de essa associação divulgar diversos trabalhos científicos em seus eventos, abrangendo pesquisas de diferentes regiões do Brasil.

Ao ponderar sobre o tema ensino coletivo de violão, surgiram algumas questões sobre as publicações nos Anais dos Encontros da ABEM: 0 que se tem investigado e relatado sobre o ensino coletivo de violão? Qual é o quantitativo anual de pesquisas e relatos de experiências por encontro? Em que nível acadêmico - graduação, mestrado ou doutorado - se desenvolveram as investigações sobre o ensino coletivo de violão? Quais são os contextos socioculturais que permeiam o desenvolvimento dessas práticas ou investigações? Ou seja, como questão de pesquisa, destaco: Quantas e quais são as características mais marcantes das publicações existentes sobre o ensino coletivo de violão nos Anais dos Encontros Anuais da ABEM?

Os objetivos específicos foram: Quantificar as publicações já realizadas no tema ensino coletivo de violão no período 2003-2017; analisar e identificar os trabalhos de pesquisa e de relatos de experiência; identificar os níveis acadêmicos em que esses trabalhos foram produzidos; caracterizar os objetivos gerais dos trabalhos, quantificar as incidências das palavras chave e identificar os contextos socioculturais.

Nas buscas realizadas por publicações na área de educação musical, incluído nos anais da ABEM, verifiquei a não existência de pesquisas bibliográficas no tema citado. Por esse motivo, esta pesquisa se torna relevante academicamente na área de educação musical.

\section{Violão no Brasil}

Em seguida, propõe-se uma contextualização histórica sobre o violão no Brasil e do seu ensino coletivo. Nesse sentido é possível encontrar muitas versões provindas de fontes históricas diversas relacionando a chegada do violão ao Brasil e o seu desenvolvimento a partir do processo de colonização. Uma dessas leituras nos diz que o violão nas suas primeiras manifestações no panorama musical do Brasil tem um vínculo inicial com o instrumento nomeado de viola. Sobre a aparição da viola no século XVII, esse instrumento de 5 cordas duplas considerado precursor do violão que foi trazido pelos jesuítas portugueses na época da colonização. A desvinculação do violão e da viola acontece a partir do século XIX, segundo Dudeque (1994), a viola se converte no que hoje conhecemos como a viola caipira, instrumento típico do interior do país. Assim, 
o violão, depois de ter passado pelo processo histórico de transformação e chegado na sua forma atual, começou a aparecer nas manifestações urbanas do país. 0 autor complementa sobre o assunto:

O violão tornou-se instrumento favorito para acompanhamento da voz, como no caso das modinhas, e, na música instrumental, juntamente com a flauta e o cavaquinho, formou a base do choro. Por ser usado basicamente na música popular e pelo povo, o violão adquiriu má fama, instrumento de boêmios, presente entre seresteiros, chorões, tornando-se sinônimos de vagabundagem. Assim o violão foi considerado durante anos (Dudeque, 1994, p. 101).

No final do século XIX, período de transição para o século XX, a cidade do Rio de Janeiro “[...] era o principal centro urbano, econômico e político do país" (Llanos, 2016, p. 229). Taborda (2011) comenta sobre o impacto social e econômico que teve a sociedade carioca desde a chegada da família imperial. Para a autora, o processo de urbanização modificou os diversos setores da sociedade, com marcadas transformações nas relações sociais e no cotidiano dos habitantes. Nesse sentido a autora também comenta sobre a disseminação do violão nos contextos urbanos, os quais iriam resultar em manifestações culturais como a aparição dos conjuntos de choro.

Nesta época surgiram os primeiros violonistas na cena musical do Rio de Janeiro, que conforme a circunstâncias se constituíram como profissionais do instrumento, colocando o violão num status social mais "elevado". Muitos desses violonistas provinham de condições humildes, como exemplo disso, encontra-se João Teixeira Guimarães (1883 - 1947) —conhecido como João Pernambuco-, sendo um dos primeiros violonistas profissionais (Pereira, 2012, p. 72). Para Pereira (2012) João Pernambuco, quem era analfabeto, teve sua estadia em 1904 no Rio de Janeiro, trabalhando inicialmente com serviços gerais como ajudante de pedreiro e trabalhos braçais. 0 autor menciona que João Pernambuco, ainda um jovem violonista, conheceu a Catulo da Paixão Cearense (1986 - 1946). A junção desses dois personagens éimportante para entender o processo da inserção do violão nas camadas da alta sociedade, pois foi através da influência de Catulo que sucedeu a "reabilitação do violão nos salões da alta sociedade" (Marcondes, 1998, p.190). Nesse sentido, Rodrigues (2002) comenta:

O sucesso de Catulo abriu-lhe portas, a ele e ao violão, que de instrumento de boêmios virou instrumento nobre. Em 1908, o violão, pelas mãos e dedos de Catulo, entrou no Instituto Nacional de Música. O Catulo, poeta e violonista, foi convidado por Nair para os saraus do Palácio. E desde o começo encantou a todos com a sua simplicidade e maestria no verso e no violão (Rodrigues, 2002, p. 75).

Para Pereira (2012) há possibilidade ainda de mencionar outros violonistas da época, embora "com menor precisão e menor número de fontes" (Pereira, 2012, p 74). Assim considera que as carreiras de Levino Albano da Conceição, Canhoto e João Pernambuco foram figuras importantes no processo de ressignificação do violão que passou de ser um instrumento marginal para um instrumento que começou a aparecer nas salas de concerto, nos cinemas, teatros e espaços públicos frequentado, na sua maioria, 
pela elite. Pereira (2012) destaca, também, que essa década foi favorável para quem queria viver como violonista, visto que havia mais aceitação por parte da crítica e pela visibilidade do instrumento nesses espaços importantes, onde podia-se apreciar o violão solo ou em conjuntos maiores.

A partir dos anos 20 o Rio de Janeiro, com uma ampla manifestação cultural de linguagem própria, mostrava-se importante para cena musical. Nesse sentido Taborda (2011) menciona que em 1922 o Rio de Janeiro começava a vivenciar, também, a incorporação do rádio. Esse fato trouxe consigo uma exigência maior a respeito do amadurecimento técnico do repertorio violonistico que se adaptou às demandas da nova tecnologia da indústria fonográfica.

Pereira (2012) atenta para a "época de ouro do rádio" como um período que ajudou a fortalecer profissionalmente à carreira dos violonistas. Nesse sentido podemos dizer que a implementação do rádio como nova tecnologia da indústria da música, trouxe maior visibilidade ao violão e por conseguinte a aparição do uma nova geração de violonistas que segundo o autor "alcançaram popularidade comparável à dos artistas populares da mídia de nossos dias" (Pereira, 2012, p. 75). Para Llanos (2016), um ponto de impacto nessa época foi a aparição da figura do ouvinte como consumidor, condicionando a disseminação hegemônica do conteúdo musical, "principalmente nas emissões radiais que submetem o país a um repertório popular massivo (e urbano, pois o epicentro radial é metropolitano), concomitante ao legado oscilante entre o erudito e o popular (tradicional e/ou folclórico)" (Llanos, 2016, p. 241). Assim o violão passa a ser um instrumento representativo da música popular no Brasil e desta mesma linha da música popular irão surgir, nas diferentes épocas posteriores, violonistas reconhecidos de diferentes regiões do país, que irão explorar no seu repertorio diversos gêneros musicais do país, indo desde o samba, choro, a Bossa Nova, entre outros estilos musicais, e em alguns casos mantendo o repertorio erudito do violão solo. Pereira (2012) destaca alguns violonistas, como:

Luis Bonfá (1922 - 2001), Paulinho Nogueira (1929 - 2003), Baden Powel (1937 - 2000), Rafael Rabelo (1962 - 2001) e atualmente representado por violonistas como Paulo Bellinati (1950), Marco Pereira (1950), Yamandu Costa (1980) e Marcus Tardelli (1977). (Pereira, 2012, p. 75).

Na literatura, é possível verificar então que o violão no cenário sociocultural é um agente cultural importante para o entendimento do processo histórico dos gêneros musicais no Brasil. Para Hodder (1998), o instrumento pode ser analisado como um ícone de impacto sócio cultural:

O violão aqui possui uma dupla condição que denominarei de instrumento-documento, pois assim desejo afirmar que é o elemento articulador de uma série de significados sociais a partir de sua existência física (enquanto objeto), e não é só depositário passivo de paixões que o defendem ou atacam, mas, como toda cultura material, constituísse num artefato ativo construído de modo a transformar materialmente, socialmente e ideologicamente (Hodder, 1998, p. 114). 
Nesse sentido, a trajetória do violão no Brasil pode ser entendida por muitos autores como uma sequência evolutiva resultante do violão na Europa, criando assim uma narrativa paralela entre os moldes europeus de se tocar o violão em comparação aos modos de se tocar no Brasil.

\subsection{Ensino coletivo de instrumentos musicais no Brasil e o violão}

Segundo Cruvinel (2008), o ensino coletivo de instrumentos no Brasil teve suas origens no período colonial, com as bandas de escravos, que posteriormente deram origem aos grupos de samba, fanfarra e choro.

Um período importante para o desenvolvimento do ensino coletivo de instrumentos musicais no Brasil, segundo Sá (2016), se dá a partir da metade do século XX. É nesse período que essa modalidade de ensino começa a ser utilizada nas instituições de ensino musical e também no campo de investigação acadêmica, através de publicações "em eventos e periódicos científicos, que abordam a temática na área de educação musical [...]" (Sá, 2016, p. 25). No Brasil o estudo sobre o assunto ensino coletivo de instrumentos tem mostrado "que essa modalidade de ensino vem ganhando espaço em projetos sociais, escolas de educação básica e também no ensino superior, contribuindo para a democratização do ensino de música em nosso país" (Sousa, 2018, p. 2). Sousa traz uma revisão bibliográfica sobre o assunto em questão, afirma que autores como “Barbosa (1996), Braga (2009), Cruvinel (2005, 2008, 2011), Galindo (2000), Leme (2012), Montandon (1992), Oliveira, E. A. J. de (1998), Oliveira, P. A. D. de (2010), Sá (2016) e Tourinho $(2002,2008,2014)$ " (Sousa, 2018, p. 2) também têm se dedicado ao estudo dessa temática em diferentes épocas e contextos sociais.

Sobre o violão nessa modalidade de ensino, para Sousa (2018) o primeiro projeto acadêmico documentado sobre ensino coletivo de violão foi realizado pela professora e investigadora Cristina Tourinho no ano 1989 na UFBA. Nessa instituição foram ministradas aulas em formato oficina para uma turma de mais de 30 pessoas.

Sobre esse projeto, Sá e Leão (2014) mencionam que foi:

A primeira experiência relatada e documentada de um curso de ensino coletivo de violão no Brasil remete ao ano de 1989, quando foi criada a primeira turma com quase 30 alunos no curso de extensão da Universidade Federal da Bahia (UFBA). Percebe-se que essa modalidade de ensino através do violão é relativamente nova e que a mesma necessita se consolidar tanto na utilização de conceitos teóricos como na sistematização e disponibilização de métodos e materiais didáticos que contribuam com essa nova prática de ensino (Sá \& Leão, 2014, p. 176).

Sousa (2018) destaca também outros projetos e experiências relevantes para o panorama de ensino coletivo de violão no país, entre elas: 
"Projeto Guri" da Secretaria de Cultura do Estado de São Paulo, criado no ano de 1995, em que o ECV surge como uma das modalidades oferecidas pelo projeto, que tem como objetivo trabalhar a sociabilidade e a autoestima dos alunos por meio das aulas de música; 2) Projeto “Orquestra Cidades" criado pelo Maestro Claudio Weizmann, por meio da Lei de Incentivo à Cultura do Governo Federal. Iniciado em 2001, o projeto foi implementado em três cidades no interior de Goiás: Catalão, Niquelândia e Barro Alto, objetivando atender 120 adolescentes em cada cidade e montar no prazo de um ano uma Orquestra de Violões em cada cidade. (Sousa, 2018, p. 4)

Ainda para o autor, trazendo um pouco das considerações de diferentes autores que estudam essa temática, o ensino coletivo de violão ajuda aos alunos aprenderem a tocar o instrumento, de maneira que, a interação com outros colegas permita a ajuda entre eles e, desse modo, possam trabalhar o aprendizado de um repertorio musical especifico. No caso especificamente do violão:

pode-se trabalhar o repertório musical tanto por acompanhamento harmônico, tanto por meio da cifra e das levadas rítmicas, onde todos tocam a mesma coisa ao mesmo tempo, ou executar arranjos instrumentais com divisões de vozes. (Sousa, 2018, p.4).

De um modo geral, nas buscas feitas, os trabalhos encontrados sobre o ensino coletivo de violão tendem a refletir a relevância dessa prática, uma vez que tem sido uma atividade recorrente em diversos espaços sociais, abrangendo desde os ambientes mais comunitários e populares até os institucionais e com reconhecimento social. Corroborando essa ideia, Sá e Leão (2014, p. 180) defendem que "um dos objetivos do Ensino Coletivo de Violão no Brasil é levar o ensino da música a uma maior quantidade de alunos; isso ocorre principalmente em projetos sociais, cursos de extensão e escolas de educação básica".

Sobre o ensino coletivo, Mello \& Pinheiro (2017) apontam à importância dos questionamentos levantados a partir das pesquisas realizadas nessa temática, uma vez que elas propiciam novas maneiras de se pensar o ensino, em contraposição do ensino tradicional. Nessa perspectiva, o autor explicam:

Diante de tantas possibilidades e recursos metodológicos para o ensino de violão na atualidade, percebemos que o ensino coletivo vem ganhando força nas discussões sobre formas de se ensinar instrumentos no Brasil. Isto se dá pelo amplo crescimento de trabalhos voltados ao ensino coletivo, o que despertou questões pertinentes para se pensar nos tradicionais moldes de se ensinar violão. (Mello \& Pinheiro, 2017, p. 2).

Para Tourinho (1995) existe um processo considerável que varia entre o ensino coletivo do instrumento em comparação ao ensino individual. A autora expressa:

A troca de ideias, dentro e fora da classe, os colegas servindo, de apoio e espelho, foram pontos fundamentais para a obtenção de resultados mais efetivos do que estudante restrito somente ao modelo de professor (Tourinho, 1995, p. 159). 
Barreto (2008) expõe também a importância desse sistema de ensino, uma vez que auxilia na democratização e acesso do ensino musical. Ainda, afirma que essa abordagem de ensino vem ganhando mais visibilidade a cada ano, tornando-se bastante desenvolvida por professores de música no país.

\section{Metodologia da pesquisa}

Para o desenvolvimento desta investigação foi empregado o método da pesquisa bibliográfica, que teve como finalidade fundamental "conduzir o leitor a determinado assunto e proporcionar a produção, coleção, armazenamento, reprodução, utilização e comunicação das informações coletadas para o desempenho da pesquisa" (Fachin, 2005, p 125).

Na exploração dos Anais dos Encontros da ABEM e nas análises das publicações existentes na mesma, entre os anos 2003 e 2017, entendeu-se como essencial o emprego do método de pesquisa bibliográfica. Foi este método que garantiu uma compilação de dados ao alcance dos objetivos propostos nesta investigação.

Este trabalho de pesquisa se desenvolveu a partir da coleta, organização e classificação das publicações existente em uma fonte específica. Como fonte das publicações a serem analisadas, delimitaram-se os Anais dos Encontros da ABEM.

Foram acessadas e analisadas as publicações que se encontram disponíveis online, gratuitamente, no site da ABEM. De acordo com o site, somente estão disponíveis os anais que compreendem os anos 2003 a 2017. Por isso, esse recorte temporal foi estipulado. A seguir, apresento as etapas para o acesso e a análise das publicações.

Etapa 1. Como procedimento inicial, acessei no site oficial da ABEM e realizei o download dos arquivos dos Anais. Selecionei as publicações que continham a expressão "ensino coletivo de violão" em seus títulos, resumos ou palavras chave. Na sequência, fiz o agrupamento das publicações disponíveis em PDF, separadas por pastas referentes a cada ano de publicação. Essa primeira etapa foi realizada a partir do mês de Maio a final Julho de 2019.

Etapa 2. Identificou-se o quantitativo total de 51 trabalhos nos Anais dos Encontros Anuais da Associação Brasileira de Educação Musical (ABEM), entre os anos 2003 e 2017. A esse material foi empregado um software de organização, classificação e análise dos dados de pesquisa qualitativa, denominado NVivo. Nesse software foram criados tabelas e quadros que mostram de maneira organizada as categorias estabelecidas e correspondentes de todas as publicações coletadas. Sobre o emprego de softwares de análise de dados, Yin (2016) explica: "Sua funcionalidade imita as etapas mais importantes na realização da análise, ainda que cada nova função também venha acompanhada de procedimentos e regras de navegação mais complicadas" (Yin, 2016, p. 161). 
Para tal classificação, o programa auxiliou na criação de nós que direcionassem informações referentes a cada categoria como: palavras chave, objetivos, contextos sociais e natureza dos trabalhos, de maneira a organizar esses dados para posteriormente serem analisados.

Os procedimentos de redação foram realizados após a classificação e análise de todo esse material por meio do software Nvivo.

Foi realizada, também, uma leitura e classificação das informações através do uso computador e software como Word, sem o emprego do Nvivo. Esse processo foi necessário devido a que, nesta etapa, estive um período fora do Brasil, sem ter acesso ao software Nvivo, tendo que dar sequência na investigação com os recursos disponíveis. Foi interessante notar, também que esse procedimento auxiliou na verificação e localização de possíveis erros na coleta dos dados e na correção dos mesmos. Essa segunda etapa foi realiza de Julho a setembro de 2019.

Etapa 3. A partir do quantitativo total de 51 trabalhos, criou-se um quadro com as referências bibliográficas de cada autor, em ordem alfabética. Em seguida no primeiro gráfico foi mostrado o percentual de publicações encontradas no assunto ao longo dos anos em que o evento ocorreu. Na sequência, identificou-se o quantitativo de incidências das palavras-chave nas publicações exibido em formato quadro. Foi apresentada, também, a lista de autores que não utilizaram palavras chave nos seus trabalhos.

Com base nos dados separados e organizados com o programa Nvivo, analisou-se o quantitativo total de trabalhos, separando-os entre aqueles que são de pesquisa e de relatos de experiência. Essas duas categorias foram apresentadas em formato tabela, expondo as referências de cada autor, junto com os objetivos referentes a cada trabalho.

Na sequência, identificaram-se os contextos sociais em que os trabalhos de pesquisa e relatos de experiência foram realizados. Para tanto, criou-se um quadro que apresentou tais informações, trazidas dos próprios trabalhos. Após, foi apresentado também o percentual em formato gráfico sobre as incidências referentes a 4 diferentes contextos: Universidade e Instituto Federal, Escola de Educação Básica, Projeto social da Prefeitura/ estado ou autônomo e Escola de música. Para complementar, optou-se por apresentar informações dos textos que confirmam os contextos citados.

Referentes aos trabalhos de pesquisa se realizou a identificação dos níveis acadêmicos. Para apresentar a informação, elaborou-se um quadro com informações de cada trabalho que justificavam a natureza de cada um. Para ilustrar esse dado foi criado um gráfico com o percentual das pesquisas referentes aos seus níveis acadêmicos, separados por trabalhos de monografias de conclusão de curso, Mestrado, Doutorado e Especialização. Trechos dos textos foram selecionados para ilustrar esse assunto. Essa última etapa foi realizada a partir do mês de setembro até dezembro de 2019.

Este trabalho não requereu a aprovação de um Termo de Consentimento Livre e Esclarecido de Pesquisa, porque não empregou seres humanos na sua coleta de dados. Além disso, todo o material a ser empregado é de acesso livre e gratuito na internet. 


\section{Resultados da pesquisa}

É importante mencionar que este artigo apresentara os dados de forma sintetizada por se tratar de uma publicação de menor proporção, cabe ressaltar que os quadros e tabelas com todos os dados em detalhes se encontram disponíveis no trabalho original de Amat y León, C. (2019). Ensino coletivo de violão: uma pesquisa bibliográfica nos anais dos encontros da ABEM entre os anos 2003-2017 (trabalho final de graduação). Universidade Federal de São Carlos, São Paulo, Brasil.

\subsection{Os trabalhos identificados nos Anais da ABEM}

Na coleta das produções que abordassem como temática o ensino coletivo de violão nos Anais dos Encontros da ABEM foi encontrado um quantitativo de cinquenta e um (51) publicações entre os anos 2003 e 2017. Ressalto que na delimitação deste período não foram coletadas as publicações do ano 2008 pela falta de disponibilidade destes Anais no site da ABEM.

Conforme a coleta realizada, constatou-se que a proporção desses trabalhos foi variável de acordo aos anos de evento. 0 ano 2003, primeiro ano a ser analisado, teve um quantitativo mínimo de apenas 1 trabalho publicado. Nos anos 2004 e 2005 foram publicados 2 trabalhos em cada. Em 2006 foram publicados 3 trabalhos. Em 2007 houve um aumento considerável para 6. No ano de 2009 foram publicados 7 trabalhos. Em 2010 houve o maior quantitativo de publicações, chegando 9 trabalhos publicados. Em 2011 houve uma queda das publicações, com apenas 5. No ano de 2013 houve 4 trabalhos. Em 2015 e 2017 foram publicados 6 trabalhos em cada ano de evento. A seguir, apresento o gráfico 1 que exibe o percentual de publicações encontradas no assunto ao longo dos anos em que o evento ocorreu.

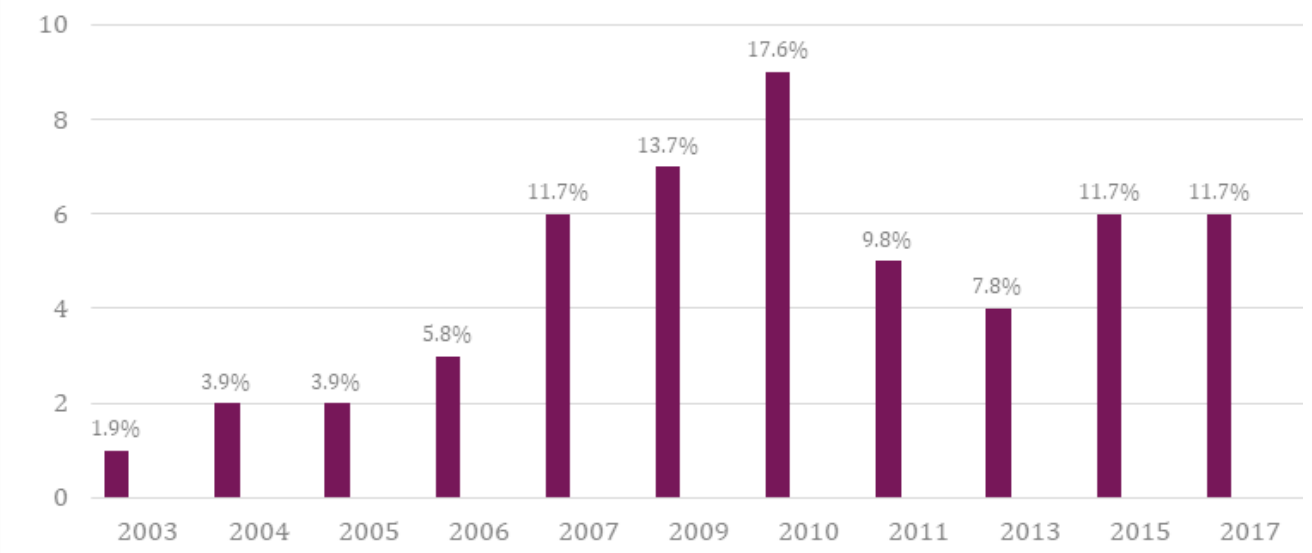

Gráfico 1: Percentual de publicações identificadas nos Anais da ABEM de 2003 a 2017. Fonte: Elaborado pelo próprio pesquisador. 


\subsection{Caracterizando as palavras-chave das publicações}

Do total de 51 trabalhos publicados, somente 42 fizeram uso de palavras chave de modo a sintetizar os temas centrais do texto. As palavras chave são apresentadas no seguinte quadro em ordem decrescente com relação aos seus quantitativos de incidência:

\begin{tabular}{|l|l|}
\hline Palavras Chave & Quantitativo de incidências \\
\hline Ensino coletivo & Em 24 publicações \\
\hline Violão & Em 23 publicações \\
\hline Educação musical & Em 10 publicações \\
\hline Aprendizagem musical & Em 7 publicações \\
\hline Escola Ensino Básico, Médio - Pratica de Conjunto & Em 6 publicações \\
\hline Música & Em 5 publicações \\
\hline $\begin{array}{l}\text { EAD - Licenciatura em Música - Metodologia e e } \\
\text { Projeto de Extensão }\end{array}$ & Em publicações \\
\hline $\begin{array}{l}\text { Socialização } \\
\text { Trabalho Colaborativo - Interação - composição - } \\
\text { autodeterminação }\end{array}$ & Em 2 publicações \\
\hline $\begin{array}{l}\text { Análise de células rítmicas - Arranjo - Contextos } \\
\text { formais de ensino - Didática - Educação profissional } \\
\text { - Espaços alternativos - Estágio - Experiência - } \\
\text { Formação de violonistas solistas - Improvisação } \\
\text { - Interpretação musical - Memória - Oficina - } \\
\text { Orquestra de violões - Repertório - Risco Social - } \\
\text { Samba - Ser humano integral - Transdisciplinaridade }\end{array}$ & \\
\hline
\end{tabular}

\section{Quadro: Quantitativo de incidências das palavras-chave nas publicações.}

Fonte: Elaborado pelo próprio pesquisador

Sobre a utilização do recuso de palavras chave, o site Enago (2019), afirma que:

Os unitermos, palavras-chave ou descritores são palavras que melhor identificam e caracterizam o trabalho a ser publicado. São as palavras mais típicas, mais usadas, descritivas de ideias ou conceitos apresentados no trabalho. As palavras-chave facilitam o trabalho de indexação de um documento. Sua preparação inadequada, juntamente com excessos e omissões, dificulta a indexação do assunto. Sua simples apresentação, para cumprir uma exigência do periódico onde se pretende publicar, não se justifica (Enago, 2019).

Apesar das palavras chave serem a menor parte de uma escrita cientifica, resumindose a 4 ou 5 palavras, elas sintetizam o conteúdo geral de um trabalho, situando os leitores sobre o mesmo. 
Nesta investigação, nem todos os trabalhos identificados na temática ensino coletivo de violão apresentaram palavras chave ou por meio delas os assuntos principais tratados nos textos. Escolhas ruins com relação às palavras chave podem acarretar dificuldades de compressão das ideias centrais dos trabalhos por parte do leitor. Fazse necessário, então, que os autores atentem ao cuidado da escolha das palavras chave.

Houveram 9 trabalhos que não fizeram uso de palavras chave e que pertencem aos Anais mais antigos disponibilizados on-line. Tal fato mostra que, com o decorrer dos anos, provavelmente os responsáveis pelas avaliações dos trabalhos que compõem os Anais da ABEM têm buscado melhorar e exigir dos autores uma padronização das publicações.

Em síntese, Treinta (2014) menciona que o pesquisador deve tomar cuidado na escolha das palavras chave nos trabalhos acadêmicos, devendo ele catalogar e guardar todo o processo a fim de garantir sempre a rastreabilidade da pesquisa.

\section{Caracterização dos tipos de publicações}

Os 51 trabalhos encontrados nos Anais da ABEM foram classificados entre pesquisas e relatos de experiência. A partir disso foi possível mapear informações sobre os seus objetivos gerais, a identificação da natureza dos trabalhos e os contextos sociais em que foram desenvolvidos.

A seguir apresenta-se a análise de trabalhos que são do tipo relatos de experiência.

\subsection{Dos trabalhos de relatos de experiência encontrados}

0 relato de experiência como modelo de escrita, tem a intenção de descrever e traçar reflexões sobre uma vivência realizada num contexto específico de modo a contribuir com considerações pertinentes à área de atuação profissional do autor, nesse sentido realizou-se a leitura e classificação dos 51 trabalhos coletados e constatou-se que 29 deles estão escritos dentro deste padrão. 18 desses trabalhos declararam ser relatos de experiência, outros 11 não fizeram essa menção, mas analisando as informações existentes em cada um deles, foi possível averiguar que eram relatos de experiência por não apresentarem metodologia de pesquisa e somente narrarem práticas e resultados de processos de ensino musical. Houveram 18 autores que especificaram o tipo de trabalho que iria a ser apresentado como artigos de relatos de experiência. Os outros 11 autores não trouxeram tal explicação de forma clara, trazendo apenas informações ao longo do texto, que induzem a pressupor tratarem-se de relatos de experiência.

Nesse sentido, é importante para os leitores dos trabalhos publicados nesse tipo de evento que as informações acerca dos mesmos sejam explicitadas de forma clara e objetiva. Considerando que 11 trabalhos não se declararam como relatos de experiência de modo direto, talvez isso gere dúvidas na compreensão dos trabalhos. 


\subsubsection{Dos relatos de experiência e seus contextos sociais}

Neste tópico descrevem-se as informações trazidas pelos autores dos 29 trabalhos de relatos de experiência a respeito dos locais onde aconteceram as práticas.

Cada autor traz informações sobre os contextos de ensino ou práticas musicais em diferentes locais, tais como: Universidades ou Institutos Federais, Projetos sociais da prefeitura, do estado ou independentes; Escolas de Educação Básica e Escolas de Música. A seguir apresento o gráfico 2 com o percentual dos locais apresentados nesses trabalhos:

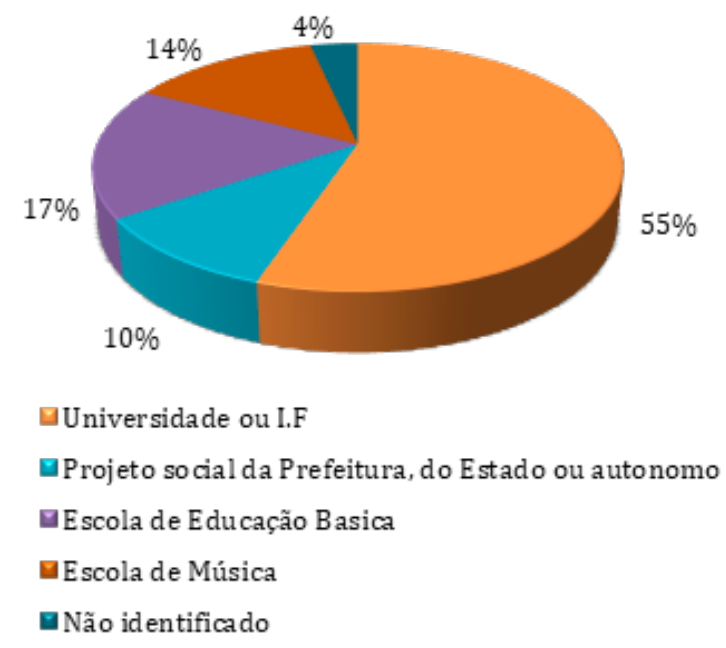

\section{Gráfico 2: Percentual da quantidade de publicações referentes aos locais onde aconteceram as práticas dos relatos de experiência.}

Fonte: Elaborado pelo próprio pesquisador.

0 gráfico apresentado mostra que a maioria dos trabalhos de pesquisa sucedem no contexto de Universidade ou Instituto Federal, tendo um quantitativo de 16 trabalhos realizados. Em seguida encontram-se 5 trabalhos no contexto de escola de educação básica. Sobre o contexto de escola de música houve 4 trabalhos. Outros 3 trabalhos que sucedem no contexto projeto social da prefeitura, do estado ou autônomo, e houve apenas um trabalho que não esclarece o contexto do local onde sucede o relato de experiência.

O quantitativo total de 16 trabalhos referentes ao contexto de Universidade ou Instituto Federal acontecem em dois âmbitos. 0 primeiro faz referência às práticas que acontecem com o grupo docente e alunos das próprias instituições dentro do próprio espaço físico. 0 segundo se refere a projetos de extensão direcionados à participação da comunidade e com um viés social. 0 gráfico 3 mostra o percentual de trabalhos desenvolvidos com a participação somente de comunidades Universitárias ou de Institutos Federais. Ainda, exibe o percentual de trabalhos que tratam de projetos de extensão realizados pelas Universidades ou Institutos Federais e que atendem comunidade interna e externa às mesmas. 

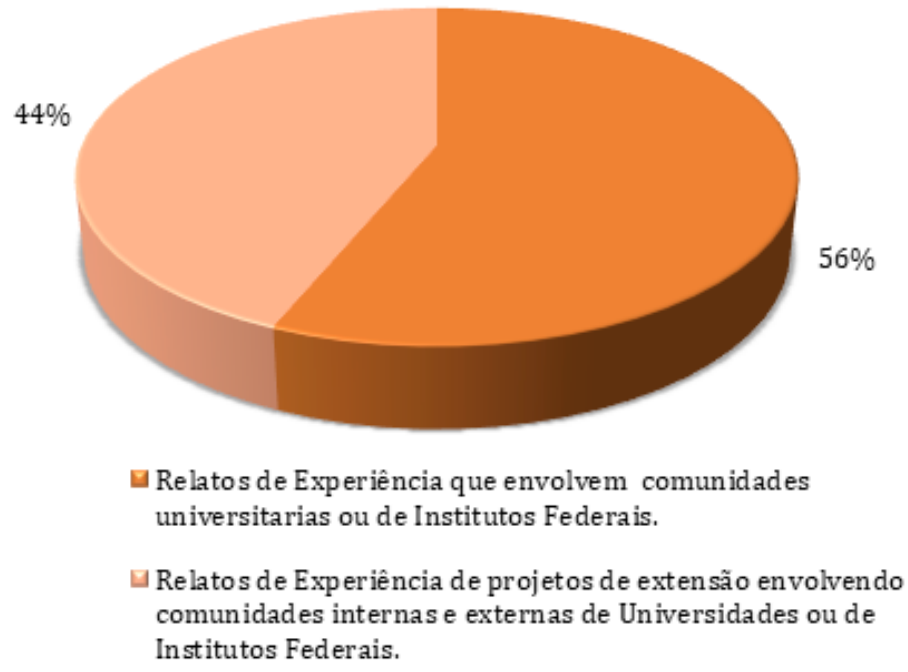

\section{Gráfico 3: Percentual de trabalhos que tratam dos contextos de Universidade e Instituto Federal.}

Fonte: Elaborado pelo próprio pesquisador.

Referente ao contexto da Universidade e Instituto Federal, 9 trabalhos envolveram apenas a comunidade interna das instituições e 7 trabalhos trataram de projetos de extensão que, englobaram a comunidade externa e interna de cada instituição.

\subsection{Pesquisas}

Dentre as publicações encontradas, identificou-se 22 que se apresentam como pesquisas. A maioria desses trabalhos apresenta algum cuidado com a descrição metodológico investigativa com a finalidade de atingir os objetivos definidos, sendo isso uma característica relevante para a classificação deste tipo de publicação constituída como pesquisa.

Os autores apresentam informações que especificam o tipo de pesquisa que desenvolvem. É possível identificar que há um número menor de pesquisas comparativamente aos relatos de experiência. Talvez seja interessante atentar ao fato de que em onze anos de publicações, referentes aos eventos nacionais da ABEM, existem apenas 22 trabalhos que investiguem a prática de ensino coletivo de violão. Ao considerar que a área de educação musical no Brasil ainda é uma área em crescimento, esperasse que essa temática apareça em um maior quantitativo nas futuras publicações nos Anais da ABEM.

\subsubsection{Dos Contextos sociais dos trabalhos de pesquisa}

Do quantitativo total de 22 trabalhos de pesquisa, 14 apresentam informações sobre os locais onde aconteceram cada uma dessas investigações. Os 8 trabalhos restantes não 
apresentaram nenhum detalhamento sobre o contexto social. Isso ocorre por trataram-se de investigações teóricas que abordam temas como análises da formação de professores e reflexões fundamentadas na literatura sobre o ensino coletivo de violão.

A partir do levantamento das informações apresentadas acerca dos locais onde os autores observaram e desenvolveram as investigações, realizou-se uma categorização sobre as incidências dos diferentes contextos identificados. A seguir apresento o gráfico 4 com o percentual de publicações referentes a cada contexto.

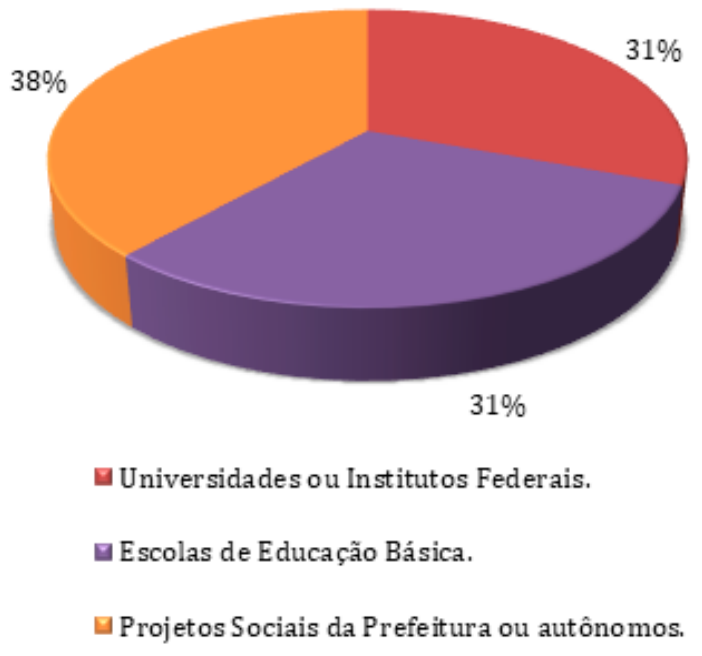

\section{Gráfico 4: Percentual de publicações referentes a cada contexto.}

Fonte: Elaborado pelo próprio pesquisador.

O quantitativo relacionado a cada contexto apresentado no gráfico corrobora a 4 pesquisas referentes ao contexto de Universidade e Instituto Federal e 4 pesquisas referentes ao contexto de Educação Básica. É importante destacar que, ao contrário dos trabalhos de relatos de experiência, o quantitativo sobre os contextos dos trabalhos de pesquisa mantém um padrão mais equitativo.

\subsubsection{Da natureza das publicações de pesquisa}

Nesta pesquisa compreende-se como natureza das publicações a origem ou filiação que elas possam ter com grupos de pesquisa, pós-graduações, graduações etc. A partir dessa perspectiva, constatou-se apenas 10 trabalhos que trouxeram tais informações sobre a natureza nas quais foram concebidas.

A seguir apresento o gráfico 5 com o percentual das pesquisas referentes as suas naturezas, divididas em 4 tópicos: Monografia de conclusão de curso, Mestrado, Doutorado e Especialização. 


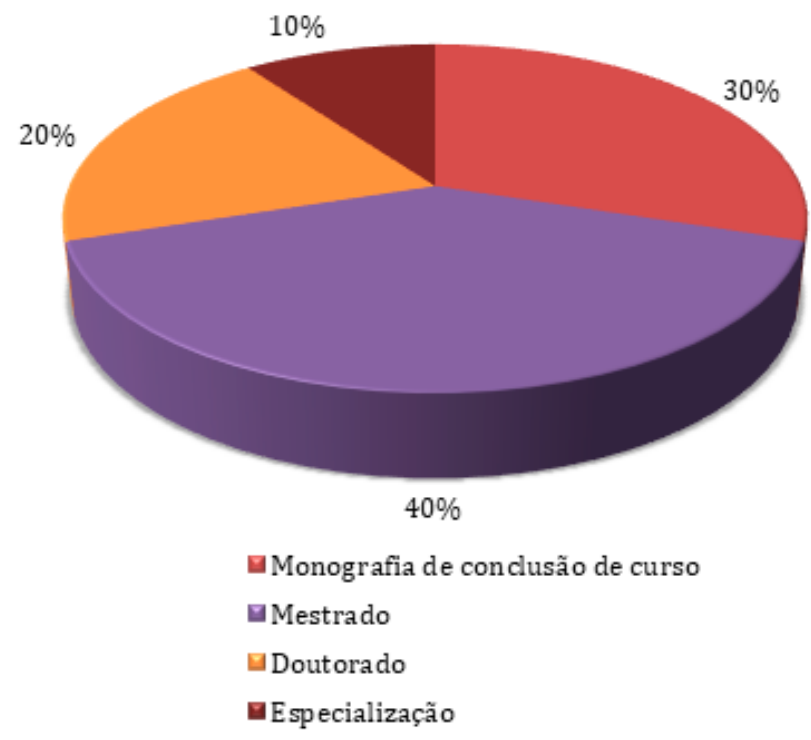

Gráfico 5: Percentual das pesquisas referentes às suas naturezas.

Fonte: Elaborado pelo próprio pesquisador.

O quantitativo referente às naturezas dos trabalhos no gráfico 5 é: 1 trabalho de especialização, 2 trabalhos de Doutorado, 3 trabalhos de Monografia de conclusão de curso e 4 trabalhos de mestrado.

No gráfico 5, observa-se que há superioridade numérica de trabalhos de pesquisa em pósgraduação publicados nos Anais da ABEM. Esses são representados com um percentual de 70\% alusivos aos trabalhos de: Mestrado, Doutorado e Especialização. Assim, as publicações de Graduação - com um percentual de 30\% em comparação aos trabalhos realizados em nível de pós-graduação - assumem um quantitativo menor e se referem especificamente a trabalhos finais de conclusão de curso.

Ainda com relação à natureza dos trabalhos, é pertinente salientar que do quantitativo total de 51 encontrados, 35, que englobam relatos de experiência e pesquisas, não apresentam informações referentes às suas naturezas de publicações.

\section{Considerações finais}

Para a realização desta investigação foi eficaz a utilização do método de pesquisa bibliográfica. É importante salientar que a dificuldade maior se encontrou no momento de interpretação dos dados, nas diferentes categorizações, pois muitas das publicações não traziam informações pontuais referentes a cada categoria, de modo que foi necessária uma análise mais extensiva referente à leitura e releitura de cada trabalho, a fim de a garantir a categorização adequada. 
No desenvolvimento desta pesquisa, percebi a importância de entender, através dos dados quantitativos, as incidências das publicações sobre o ensino coletivo de violão. Nesse sentido, pode-se verificar que em 11 anos de publicações nos Anais da ABEM, há apenas 51 trabalhos divididos entre 22 pesquisas e 29 relatos de experiência, que discorrem sobre tal assunto. Possivelmente, o motivo de haver um quantitativo consideravelmente baixo, esteja ligado ao processo de estruturação e consolidação dessa pratica no meio acadêmico e fora dele. Embora o violão seja um instrumento musical aparentemente popular no país, os dados mostram que essa popularidade, ainda não se reflete no quantitativo de publicações de educadores musicais que queiram debruçar sobre tal pratica. Nesse sentido, espera-se que o ensino coletivo de violão, como objeto de investigação e relatos de experiência, tenha uma configuração crescente nos futuros anos de publicação nos Anais da ABEM.

Ponderando sobre os contextos das práticas de ensino coletivo de violão mencionadas nos trabalhos, pode-se concluir que as mesmas acontecem em diversos espaços sociais. Assim é de se considerar que o ensino coletivo de violão possa estar tendo o papel relacionado à democratização do ensino de música no país. Entretanto é necessário mencionar que esta pesquisa, ao analisar somente as publicações dos Anais da ABEM, entre os anos 2003 e 2017, representa apenas um recorte de realidade educacional vista apenas por uma fonte. Assim, atenta-se para que futuras investigações analisem a temática, em diferentes fontes de divulgação científica.

Os eventos nacionais da Associação Brasileira de Educação Musical vêm se mostrando como espaços importantes de divulgação cientifica dessa área no país. A ABEM organiza ações e divulga a produção de conhecimento, estimulando a troca de conhecimentos e resultados à respeito das práticas educacionais entre os profissionais dessa área de conhecimento. Considerando então, sobre a importância da ABEM como uma das fontes de maior divulgação de conhecimento na área de educação musical, a partir desta pesquisa, pode-se levantar a hipótese de que as informações trazidas aqui revelem uma boa parte da realidade nacional sobre a educação musical através do ensino coletivo de violão. Assim, para que tal hipótese seja certificada, caberia ampliar a presente pesquisa numa investigação de maiores proporções, abrangendo os anais regionais dos encontros da ABEM. Além disso, vale considerar pesquisas sobre as diversas fontes de divulgação cientifica na área de educação musical, de modo a certificar o quantitativo de incidências sobre as práticas de ensino coletivo de violão.

Sobre a importância em realizar este tipo de pesquisas, a autora Martínez (2013) aponta para a necessidade das revisões bibliográficas na área de educação musical uma vez que ainda há um percentual muito baixo de autores que as realizem. Assim, a respeito deste tipo de trabalho, a autora menciona que:

Procura contribuir com a área apresentando um panorama geral dessas publicações e suas características principais, revelando como o ensino de música tem sido pensado e como ele ocorre no Brasil e em que os profissionais da área baseiam suas práticas. (Martínez, 2013, p.10) 
Destaco também sobre a importância deste trabalho de conclusão de curso na minha formação como investigador na área de educação musical, por tratar-se de uma temática a respeito das práticas utilizadas por mim como professor e musico. Assim foi através desta investigação que conheci a literatura existente sobre ensino coletivo de violão, a qual trouxe reflexões sobre a existência de diferentes formas de desenvolver o ensino coletivo de violão considerando as características de cada contexto e, a partir desses diferencias, entender as multiplicidades de objetivos propostos por cada autor na aplicação destas práticas de ensino musical. Desse modo, aponto para a possibilidade de continuação desta pesquisa no âmbito de pós-graduação, procurando entender com maior profundidade, e por meio de diversas fontes, aspectos relevantes sobre as práticas de ensino coletivo de violão, colocando como possíveis objetivos: 1) verificar qual seria o percentual se compararmos a quantidade de estudos voltados para o ensino coletivo de violões com a totalidade de publicações presentes nos Anais da ABEM do período elencado. Outro possível objetivo 2) verificar qual seria o resultado da comparação entre a quantidade de estudos focados no ensino coletivo de violões com os estudos que trabalham com relatos e pesquisas voltadas para o ensino coletivo de outros instrumentos. Ao fazer esse comparativo e analisar também a partir desses dois dados, talvez possa-se chegar à conclusão que os trabalhos referentes ao ensino coletivo de violões se tornam bastante significativos se pensarmos que há uma infinidade de outros instrumentos que podem não ser abordados a partir do ensino coletivo.

Espera-se que a temática do ensino coletivo de violão seja ponderada por futuras investigações, considerando que essa pratica tem se mostrado aplicável nos diferentes contextos sociais como: Universidade, Instituto federal, Escolas de educação Básica, projetos sociais etc., democratizando assim o conhecimento do ensino musical.

\section{Referências}

Barreto, M. S. T. (2008). Ensino Coletivo de Violão: Diferentes Escritas no Aprendizado de Iniciantes (Trabalho de conclusão de curso - Licenciatura em música). Universidade Federal do Estado do Rio de Janeiro, Rio de Janeiro, Brasil.

Cruvinel, F. M. (2008). O Ensino Coletivo de Instrumentos Musicais na Educação Básica: compromisso com a escola a partir de propostas significativas de Ensino Musical. In anais do VIII Encontro Regional Centro-Oeste da ABEM, 1옹 Simpósio sobre o Ensino e a Aprendizagem da Música Popular e III Encontro Nacional de Ensino Coletivo de Instrumento, Brasília, 21-23 de Agosto.

Dudeque, N. E. (1994). História do violão - Norton Dudeque. Curitiba: UFPR (Universidade Federal do Paraná). 
Enago Academy (2019). A importância da correta escolha das palavras-chave. Disponível em: https://www.enago.com.br/academy/a-importancia-da-corretaescolha-das-palavras-chave Acesso em 20 nov. 2019.

Fachin, O. (2005). Fundamentos de metodologia. São Paulo: Saraiva.

Tourinho, A. C. (1995). Motivação e o desempenho escolar na aula de Violão em grupo: Influência do repertório de interesse do aluno (Dissertação de Mestrado). Universidade Federal da Bahia, Bahia, Brasil.

Hodder, I. (1998). The Interpretation of Documents and Material Culture. In Denzin, N. K. \& Lincoln, Y. S. (Eds.), Collecting and Interpreting Qualitative Materials. Thousand Oaks, CA: Sage Publications, 110-129.

Llanos, C. F. E. (2016). Violão e identidade nacional: a "moral" do instrumento. Revista da Tulha, 2(2), 227-250.

Marcondes, M. A. (1998). Enciclopédia da música brasileira: popular, erudita e folclórica. São Paulo, SP: Art Editora.

Martínez, D. É. G. (2013). As metodologias de ensino musical e suas incidências nos anais da ABEM (Trabalho de conclusão de curso - Licenciatura em música). Universidade Federal de São Carlos, São Carlos, Brasil.

Mello, D. \& Pinheiro, C. A. (2017). O ensino coletivo de violão: Um relato de experiência sobre vivências, estratégias e propostas de ensino em uma turma com crianças. In anais da XI Conferência Regional Latino-Americana de Educação Musical da ISME, Natal, 8-11 de Agosto.

Pereira, M. F.. (2012). De maldito a erudito: caminhos do violão solista no Brasil. Composiçao: Revista de Ciência Sociais da UFMS, 6(10), 68-91.

Rodrigues, A. E. M. (2002). Nair de Teffé: vidas cruzadas. Rio de Janeiro: Editora FGV.

Rodrigues, W. (N.d.). Ensino Coletivo de Violão. Disponível em: https://es.scribd. com/document/258956797/Ensino-Coletivo-de-Violao-Weslei Acesso em: 15 Set. 2019.

Sá, F. A. da S. (2016). Ensino coletivo de violão: uma proposta metodológica (Dissertação Mestrado em Música). Escola de Música e Artes Cênicas, Universidade Federal de Goiás, Goiânia.

Sá, F. A. da S. \& Leão, E. (2014). Escolha do repertório como fator que determina o nível de interesse do aluno no estudo do violão - um relato de experiência. In anais da IV Jornada de Estudos em Educação Musical e II Simpósio de Educação Musical e Humanização da UFSCAR, São Carlos, 15 de Setembro.

Sousa, H. F. de (2015). 0 violão Brasileiro e sua trajetória: Uma pequena revisão bibliográfica. In anais do $13^{\circ}$ Colóquio de Pesquisa do PPGM/UFRJ, Rio de Janeiro. 
Sousa, L. F. de (2018). 0 ensino coletivo de instrumento musical: o violão. In anais do XV Encontro Regional Centro-Oeste da ABEM, Goiânia, 25-27 de Outubro.

Taborda, M. (2011). Violão e identidade nacional: Rio de Janeiro 1830-1930. Rio de Janeiro: Civilização Brasileira.

Taborda, M. (2020). Aspectos marcantes da presença do violão na cultura brasileira. Disponível em: https://www.mvim.com.br/artigo/aspectos-marcantes-dapresenca-do-violao-na-cultura-brasileira/ Acesso em: 20 Jul. 2019.

Treinta, F. T, Filhos, J. R. F, Parracho, S. A \& Rabelo, L. M (2014). Metodologia de pesquisa bibliográfica com a utilização de método multicritério de apoio à decisão. Production, 24(3), 508-520.

Yin, R. K. \& Dirceu da Silva, D. B. (2016). Pesquisa qualitativa do início ao fim. Porto Alegre, RS: Penso, 2016. 